\title{
O ENSINO MÉDICO E A CRISE NOS HOSPITAIS UNIVERSITÁRIOS
}

\section{MEDICAL EDUCATION AND UNIVERSITY HOSPITAL'S BREAKDOWN}

\author{
Umberto Perrotta, ECBC-RJ \\ Professor Emérito da Faculdade de Medicina da UFRJ \\ Membro Emérito da do Colégio Brasileiro de Cirurgiões
}

\begin{abstract}
O ensino médico atravessa uma crise de conseqüências lesivas para a Universidade Pública e para a população carente, no ano em que se comemora o bicentenário das primeiras escolas médicas no país.

Com a chegada de D. João VI no Brasil, em 1808, estabeleceram-se, mediante ato da Regência, em 18 de fevereiro desse ano, os Cursos de Cirurgia e Anatomia na Bahia, e, no dia 5 de novembro ,os cursos de Anatomia e Cirurgia no Rio de Janeiro.
\end{abstract}

Em 3 de outubro de 1832, foram criadas as Faculdades de Medicina do Rio e da Bahia. Antes, no Rio de Janeiro, tinha sido instituída a Academia Médico-Cirúrgica do Rio de Janeiro, que poderia emitir diplomas. Só muito tardiamente, foi criada a Universidade do Rio de Janeiro, em 7 de setembro de 1920, por decreto do Presidente Epitácio Pessoa, tendo sido a $1^{\text {a }}$ Universidade Brasileira. A Universidade do Rio de Janeiro englobava a Faculdade de Medicina, a Faculdade de Direito e a Escola de Engenharia.

A Faculdade de Medicina não tinha sede própria, funcionando inicialmente no Hospital Militar no Morro do Castelo, posteriormente na atual Rua Evaristo da Veiga, na Santa Casa de Misericórdia e no Instituto Anatômico. Somente em 1918, foi inaugurado o prédio-sede da Praia Vermelha, pelo Presidente Wenceslau Braz.

Em 5 de julho de 1937, a Universidade do Rio de Janeiro passou a chamar-se Universidade do Brasil, (agora englobando 15 unidades universitárias) nome que perdurou até 1965, quando passou a ser Universidade Federal do Rio de Janeiro. (UFRJ).

Em 1973 com a venda do prédio-sede da Faculdade de Medicina da Praia Vermelha à Eletrobrás e a sua posterior demolição cometeu-se um atentado ao ensino médico, um crime contra a Cultura e o Patrimônio Histórico, cujos efeitos persistem.

A Faculdade de Medicina da UFRJ até hoje não tem sede. O Gabinete do Diretor da Faculdade funciona em sala do Centro de Ciências da Saúde. Se perguntarem aos alunos onde fica a Faculdade de Medicina da UFRJ, eles não saberão responder.

Durante longo tempo, a Faculdade de Medicina não tinha hospital próprio. As Cadeiras Clínicas estavam distribuídas em diversas instituições hospitalares, e principalmente localizadas na Santa Casa de Misericórdia, no Hospital Estácio de Sá (Hospital da Polícia Militar do Rio de Janeiro), no Hospital Moncorvo Filho, no Hospital São Francisco de Assis, na Maternidade Escola, no Instituto de Neurologia Deolindo Couto, no Instituto de Psiquiatria.

Iniciou-se, na década de 70, um movimento pelo Hospital Universitário, do qual participaram professores, alu- nos e funcionários, estando na liderança do movimento o professor Clementino Fraga Filho, que merecidamente dá seu nome ao Hospital Universitário. O movimento pelo $\mathrm{HU}$ foi feito exclusivamente pelos professores,alunos e funcionários da Faculdade de Medicina.

Com a Reforma Universitária de 1965, foram criados os Cursos de Pós - Graduação Senso Strictu e Senso Lato. (Os primeiros, Mestrado e Doutorado, e os outros, de Atualização e Especialização (Residência Médica) Extensão e Aperfeiçoamento).

A Constituição determina que a Universidade se destine ao Ensino, Pesquisa e Extensão, mas infelizmente, quer a pesquisa clínica, e a experimental estão prejudicadas pela falta de recursos, e pela precariedade do HU, o que torna inoperantes os cursos de mestrado e doutorado.

Os professores e funcionários são mal remunerados, as instalações hospitalares estão em ruínas, os aparelhos necessitam de reparos. As substituições não se fazem, e isto está diminuindo a eficácia e o número dos atendimentos. $\mathrm{Na}$ UFRJ, basta visitar o HUCFF, ou o Prédio da Reitoria da Praia Vermelha, o Instituto de Neurologia Deolindo Couto, a Maternidade - Escola, o Instituto de Psiquiatria, para observar que esses imóveis necessitam de obras imediatas.

O Governo Federal lançou há um ano, o Plano de Desenvolvimento da Educação, que até hoje não surtiu efeito, pois o Ensino Fundamental continua deficiente e o Ensino Superior a se deteriorar.

Também como projeto do Governo Federal, surgiu em 2007 o Programa de Apoio a Planos de Reestruturação e Expansão das Universidades Federais - Reuni - que não teve o apoio dos professores e alunos e que até hoje também não se fez sentir em obras de infra-estrutura e modernização de laboratórios.

Faz parte do Plano de Desenvolvimento da Educação o ProUni, que somente vem beneficiar os empresários do ensino, as falsas entidades filantrópicas, nada acrescentando a melhoria do ensino Superior. É o Estado socorrendo as entidades particulares, em detrimento da Escola Pública. Haveria redução ou abolição dos impostos das instituições privadas em troca de abertura de vagas. É o caminho mais rápido para a privatização do ensino superior.

A independência política e econômica de um país está na razão direta do desenvolvimento e do incentivo dado à pesquisa, que deve andar de mãos dadas com a extensão.

Recentemente, levantamento realizado pela Fundação de Administração da USP, Universidade de São Paulo demonstra em apreciação comparativa entre Brasil, Argentina, Chile, Colômbia e Venezuela, que o Brasil é o que menos investe em sistemas de saúde. 
Pesquisa Nacional por amostra de domicílios de 2003 revela que somente $24,6 \%$ dos brasileiros tinham plano de Saúde. Isto significa que 75,4 \% dependem de Serviços públicos hospitalares. O Brasil investe $8 \%$ da arrecadação pública em Saúde, enquanto o México investe $24 \%$ e a Argentina $18 \%$.

O Estado do Rio de Janeiro gasta mais dinheiro com o Legislativo e o Judiciário, que com Saúde, Educação e Segurança Pública. Enquanto que com o Legislativo e o Poder Judiciário em 2007, nosso país gastou 5 bilhões de reais, com a Saúde e a Segurança Pública, gastou 2,5 bilhões. De cada 100 reais de impostos em 2007, 25 reais foram para o Legislativo e o Judiciário.

A crise atinge todos os Hospitais Universitários, o que prejudica não só o ensino médico, mas também os Cursos de Fonoaudiologia, de Fisioterapia, de Nutrição e de Enfermagem, já que todos são ministrados no Hospital Universitário.

O movimento de protesto dos professores, alunos e funcionários é justo, necessário e patriótico, pois é movimento em defesa dos direitos do cidadão, da Saúde e da Escola Pública. 